\title{
Very low birthweight boys at the age of 19
}

\author{
Anders Ericson, Bengt Källén
}

\begin{abstract}
Using linked data from the Swedish Medical Birth Registry and the National Service Enrolment Register, long term follow up (to 18-19 years age) was made of 260 surviving singleton boys whose birthweight was less than $1500 \mathrm{~g}$ from a total of 150229 boys born between 1973-5. These boys were shorter and lighter than boys who weighed more at birth, they had more visual and hearing impairments, were at much higher risk of cerebral palsy and other signs of mental impairment, evident as lower intelligence test scores and shorter schooling. No significant excess of asthma, back problems, or headaches were found.
\end{abstract}

(Arch Dis Child Fetal Neonatal Ed 1998;78:F171-F174)

Keywords: very low birthweight; length and weight; cerebral palsy; mental development

Very low birthweight (VLBW) infants (less than $1500 \mathrm{~g}$ ) used to have a high mortality. Among VLBW infants born in Sweden between 1973-5 less than $60 \%$ survived their first year of life. ${ }^{1}$ Such infants also have an increased risk of major handicaps. Since the early 1970 s, survival has increased and the rate of handicap in surviving infants has decreased. ${ }^{2}$ Most follow up studies are of hospital populations - infants admitted to neonatal intensive care units.

Weir et al followed up 908 liveborn babies with a birthweight of $<1750 \mathrm{~g}$ born in Scotland in 1984 to the age of 4.5 years. ${ }^{34}$ Among surviving children $(71 \%), 16 \%$ were disabled. A higher prevalence of poor neuromotor competence was found among those who were not overtly disabled. In a small study from Sweden 14 VLBW infants born in 1979 and 1981 were reported at the age of 9-11 years..$^{5}$ The cases performed significantly worse than the controls.

When school performance in children with low birthweight was compared with that of normal birthweight children, lower attention scores, language skills, scholastic competence and higher daydreaming and hyperactivity scores were found in the low birthweight group. ${ }^{6}$ Effects were strongest in extremely low birthweight infants $(<1000 \mathrm{~g})$. A follow up of school performance in 813 very premature (<32 completed weeks) and very low birthweight infants showed that at the age of 9 years $19 \%$ of the children were in special education and among the remainder a large percentage experienced school problems and needed extra support. ${ }^{7}$ VLBW infants were more than four times as likely to require special education in a London population than normal birthweight infants, but the contribution of VLBW infants to the total number of children needing such support was small. ${ }^{8}$

Powls et al studied children at the age of 12 to 13 years weighing under $1250 \mathrm{~g}$ at birth. ${ }^{9}{ }^{10}$ Their stature was shorter and $34 \%$ had some clinically significant impairment compared with 5\% among controls. Quality of life score was assessed in 85 young adults born in 1971-4, weighing under $1500 \mathrm{~g}$, and treated at one unit in Copenhagen and compared with infants of a birth weight above $2500 \mathrm{~g} .{ }^{11}$ Among those free of handicap, no difference in quality of life scores was seen, but in the VLBW group an increased proportion of handicap was present. Among 591 VLBW infants born in 1983-6 in and around Hamburg, Germany, 330 were traced at the age of 6: 19 were severely disabled and 289 were investigated psychologically. ${ }^{12}$ The mean memory performance was below the standard in all groups.

Few studies have followed up such infants into adolescence. Stewart and Kirkbridge followed up 142 very preterm infants $(<33$ weeks) with ultrasound and magnetic resonance image scanning to the age of 14-15 years. ${ }^{13} \mathrm{~A}$ study of 137 VLBW infants followed up to the age of 12 showed that growth problems persist, with shorter body length, lower weight, and smaller head circumference than those of 160 control children. ${ }^{10}$

We have used material obtained by record linkage of a medical birth registry ${ }^{14}$ and medical examination data recorded in the National Service Enrolment Register. At the age of 18-19, most young men in Sweden are examined by a physician and a psychologist, to establish their fitness for national service. In principle, national service is compulsory for all boys, even though exemptions are made for various reasons. After record linkage, prenatal and perinatal data were available on most boys born in Sweden and listed in the National Service Enrolment Register. For this study we selected boys with a birthweight below $1500 \mathrm{~g}$.

Similar methodology was used in Israel in a study of 30312 men at medical draft examination: an increased risk of asthma in boys whose birthweight was low was found. ${ }^{15} \mathrm{~A}$ Danish conscription registry is also available which has been used in medical studies. ${ }^{16}$

\section{Methods}

The Medical Birth Registry has existed in Sweden since 1973, comprising nearly all $(99 \%)$ births. It contains extensive data on pregnancy, delivery, and the paediatric examination of the neonate. ${ }^{14}$ In 1973-5, 325292 infants were born in Sweden according to official statistics. Among them, 322223 (99.1\%) were registered with correct maternal and infant identification. Identification is obtained 


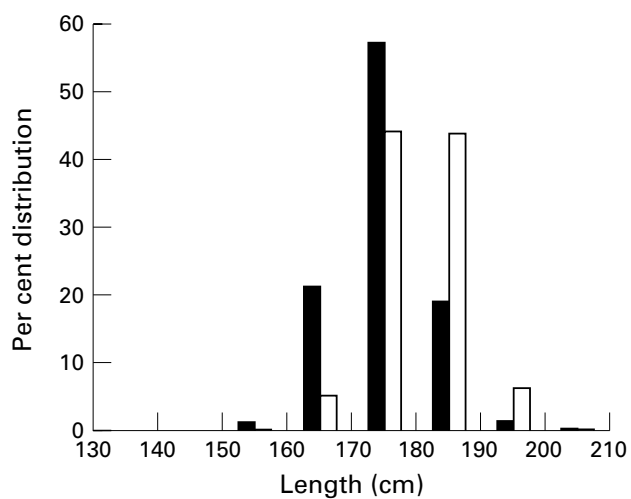

Figure 1 Per cent distribution of body length in VLBW weight boys (shaded columns) up to $210 \mathrm{~cm}$ and all other boys.

from the unique personal identification number supplied to everyone living in Sweden. Maternal education level on 1 January 1996 was obtained from the Swedish Registry of Education.

Among infants registered for 1973-5, 166 177 were boys 3498 of whom died before the age of 19. A total of $150229(92 \%)$ had data on the register from medical and psychological examinations at military service enrolment for the years 1992-5. The missing individuals may have emigrated or have had erroneous identification numbers, but this group also includes individuals who had been excused from the examination due to severe handicap or chronic diseases. The records from national service enrolment contain numerous medical and psychological details and also up to six medical diagnoses given as standard ICD-9 codes. In $5565(3.7 \%)$ a medical diagnosis only was given and no further medical examination was made. Boys with mental retardation or severe physical handicap such as cerebral palsy were included among this category.

Among 317 surviving singleton boys with a stated birthweight $<1500$ g, 289 were identified $(91 \%)$. The risk ratio of not being entered on the National Service register at VLBW compared with normal weight babies is 1.17 (95\% confidence interval of $0.79-1.72$ ). In other words there is a slight and insignificant selective dropout of VLBW infants from the study. If the general dropout rate is applied to the 317 surviving boys, one would expect 293

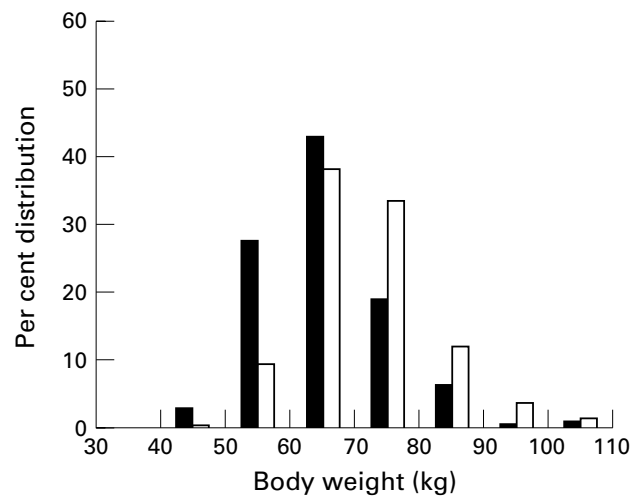

Figure 2 Per cent distribution of body weight up to $110 \mathrm{~kg}$ in VLBW boys (shaded columns) and all other boys.
Table 1 Muscular strength (Newton) in 223 VLBW boys and expected numbers calculated from total population

\begin{tabular}{llll}
\hline Group & Definition & Observed & Expected \\
\hline 1 & $<971$ & 0 & 0.04 \\
2 & $972-1315$ & 3 & 0.06 \\
3 & $1316-1707$ & 43 & 0.33 \\
4 & $1708-1952$ & 66 & 14.75 \\
5 & $1953-2099$ & 38 & 44.13 \\
6 & $2100-2246$ & 37 & 69.43 \\
7 & $2247-2345$ & 22 & 60.86 \\
8 & $2346-2443$ & 8 & 30.82 \\
9 & $2444-$ & 10 & 11.44 \\
\hline
\end{tabular}

instead of the 289 present - a selective loss of only four individuals.

The records of the infants with a stated birthweight below $1500 \mathrm{~g}$ were scrutinised for data mistakes $^{1}$ and 29 such cases were identified and removed, leaving 260 VLBW boys born as singletons. This percentage $(10 \%)$ of miscoded birthweights below $1500 \mathrm{~g}$ is similar to that found before and arises from the fact that even a low rate of miscoding of a normal birth weight ( $4400 \mathrm{~g}$ to $1400 \mathrm{~g}$ ) will result in a relatively high percentage of wrong birthweights in the small group of infants with a weight $<1500 \mathrm{~g}$. These VLBW boys were compared with all singletons for the following outcomes:

- body length, body weight, and body mass index

- muscular power and physical work capacity. Each was classified in nine groups and divided above and below 1953 Newton (category 5 among 9) and above or below 4 Watt/kg (category 5 among nine). These limits were chosen to separate out the subgroup with the lowest muscular strength ( $7 \%$ of the population) and the subgroup with the highest physical work capacity ( $20 \%$ of the population).

- vision tests and diagnoses

- hearing tests and diagnoses

- some other medical diagnoses

- intelligence score and schooling. There is a nine item scale with $7.5 \%$ of the population below five; 6 represents the median (and mode) value in the population.

For each characteristic the observed numbers among the VLBW infants were compared with the expected numbers calculated from all individuals on file. For most conditions, a stratified analysis was also performed using the Mantel-Haenszel method. ${ }^{17}$ Stratification was made for year of birth, maternal age and parity, and maternal education. The results of these analyses are presented as odds ratios (OR) with 95\% confidence intervals (95\% CI) calculated with a test based method. ${ }^{18}$

Table 2 Physical working capacity (watt/kg body weight $\times$ minutes) in 218 VLBW boys and expected numbers calculated from total population

\begin{tabular}{llll}
\hline Group & Definition & Observed & Expected \\
\hline 1 & $<1.9$ & 0 & 0.36 \\
2 & $2.0-2.4$ & 2 & 1.47 \\
3 & $2.5-2.9$ & 6 & 5.20 \\
4 & $3.0-3.4$ & 18 & 14.87 \\
5 & $3.5-3.9$ & 42 & 36.76 \\
6 & $4.0-4.3$ & 126 & 94.98 \\
7 & $4.4-4.7$ & 3 & 20.68 \\
8 & $4.8-5.1$ & 10 & 19.72 \\
9 & $5.2-$ & 11 & 22.95 \\
\hline
\end{tabular}


Table 3 Diagnoses referring to visual impairment in 260 $V L B W$ boys and expected numbers calculated from total population

\begin{tabular}{llll}
\hline ICD diagnosis & Definition & Observed & Expected \\
\hline 3660 & Cataract & 1 & 0.02 \\
3670 & Hyperopia & 9 & 4.8 \\
3671 & Myopia & 15 & 5.2 \\
3672 & Astigmatism & 6 & 4.5 \\
3678 & Other refraction error & 1 & 0.6 \\
369 & Severely reduced & 18 & 6.1 \\
$\quad$ vision & 6 & 0.6 \\
\hline 378 & Strabismus & 6 & \\
\hline
\end{tabular}

\section{Results}

BODY LENGTH, BODY WEIGHT, AND BODY MASS INDEX

Figure 1 shows that the body length distribution at the age of 18-20 years of the VLBW boys has shifted to the left compared with those born weighing over $1500 \mathrm{~g}$. The OR for having a length below $170 \mathrm{~cm}$ (stratifying for year of birth, maternal age, parity, and education) was 4.8 (95\% CI 3.6-6.5). Figure 2 shows the corresponding diagram for body weight, again with a clearcut shift towards the left. The OR for weighing below $65 \mathrm{~kg}$ was 3.6 (95\% CI 2.8-4.7).

The mean body mass index (BMI = weight/ length ${ }^{2}$ ) was calculated. In the VLBW group it was 21.19 (SEM 0.19) and in the total population the mean was 22.61 (SEM 0.37). BMI was thus significantly lower in the VLBW group $(\mathrm{p}<0.001)$.

\section{MUSCULAR STRENGTH AND PHYSICAL WORK CAPACITY}

Muscular strength expressed in Newton was estimated from tests of three muscular groups: hand grip, knee extension, and elbow flexion, and was grouped into 10 groups (table 1). There was a clearcut reduction in muscular strength. The OR for muscular strength below the 1953 Newton score was 2.7 (95\% CI 2.13.5).

When physical work capacity was evaluated (table 2) relatively small differences between observed and expected values were found

Table 4 Results of hearing tests in 223 VLBW boys and expected numbers calculated from total population

\begin{tabular}{|c|c|c|c|}
\hline Group & Definition & Observed & Expected \\
\hline 1 & $\begin{array}{l}\text { Average hearing loss in best ear at } 500,1000, \\
\text { and } 2000 \mathrm{~Hz} \text { between } 40-60 \mathrm{db}\end{array}$ & 1 & 0.1 \\
\hline 2 & $\begin{array}{l}\text { Average hearing loss in best ear at } 500,1000 \text {, and } \\
2000 \mathrm{~Hz} \text { between } 20-40 \mathrm{db}\end{array}$ & 8 & 3.2 \\
\hline 3 & $\begin{array}{l}\text { Hears } 20 \mathrm{db} \text { at } 500,1000 \text {, and } 2000 \mathrm{~Hz} \text { in best } \\
\text { ear and loss } 20-40 \mathrm{db} \text { worse ear }\end{array}$ & 6 & 3.5 \\
\hline 4 & $\begin{array}{l}\text { Hears } 20 \mathrm{db} \text { at } 500,1000,2000 \text {, and } 3000 \mathrm{~Hz} \\
\text { both ears }\end{array}$ & 34 & 27.4 \\
\hline 5 & $\begin{array}{l}\text { Hears } 20 \mathrm{db} \text { at } 500,1000,2000,3000 \text {, and } 4000 \\
\text { Hz both ears }\end{array}$ & 174 & 189.9 \\
\hline
\end{tabular}

Table 5 Some medical diagnoses given to $260 \mathrm{VLBW}$ boys showing observed numbers and expected numbers from all boys and odds ratios (OR) stratified for year of birth, maternal age and parity, and maternal education

\begin{tabular}{lllll}
\hline \multirow{2}{*}{ ICD code } & \multirow{2}{l}{ Numbers } & & \\
\cline { 3 - 5 } & Diagnosis & Observed & Expected & OR $(95 \%$ CI $)$ \\
\hline $342-344$ & Cerebral palsy & 18 & 0.3 & $55.4(40.8-75.2)$ \\
$317-319$ & Mental retardation & 4 & 2.0 & $1.7(0.5-5.1)$ \\
345 & Epilepsy & 4 & 1.5 & $2.6(0.7-6.8)$ \\
493 & Asthma & 16 & 15.5 & $1.1(0.6-1.8)$ \\
$724+737$ & Spine/back problems & 23 & 21.4 & $1.1(0.7-1.7)$ \\
$346+484.0$ & Headache, migraine & 12 & 11.6 & $1.1(0.6-1.9)$ \\
\hline
\end{tabular}

except for the two highest groups: 21 observed against 43.4 expected. This variable was corrected for body weight. The OR of a value below 7 was 3.3 (95\% CI 2.2-5.1).

VISION

Vision tests were scored on a scale from 1 to 9 , where 9 is full vision (1.0) in both eyes. Below 7 , corrective lenses are needed. The OR of a vision score below 7 was 1.4 (95\% CI 1.0-1.8).

The clinical diagnosis of blindness (where vision tests were not necessarily made) occurred in 18 cases among VLBW boys and in 242 other boys. The OR was 2.8 (95\% CI 1.74.6).

For all those studied (including those who were not examined with vision tests), diagnoses referring to vision were given in 38 (expected number 16.6). The OR was 2.6 with a $95 \%$ CI of 1.8-3.6. Table 3 shows the distribution of such diagnoses. As one individual can have more than one diagnosis, the total number of diagnoses exceeds the total number of individuals. There was a clear excess of myopia (OR 3.3, 95\% CI 2.0-5.5) and an indicated but non-significant excess of hyperopia (OR 1.8, 95\% CI 0.9-3.6).

HEARING

Table 4 shows the results of hearing tests. The outcome is clearly worse than expected in the VLBW group. Relatively severe hearing loss was found in 15 individuals against the expected number of 6.6. The OR for this was 2.5 (95\% CI 1.2-5.0).

A clinical diagnosis of impaired hearing was given to 48 VLBW boys and 212 others which gave an OR of 1.5 (95\% CI 1.1-2.0).

\section{MEDICAL DIAGNOSES}

Table 5 lists some medical diagnoses which were common enough to permit comparisons. Expected values from the total number of boys and odds ratios calculated after stratification are also shown.

Cerebral palsy was noted in 18 cases $(6.9 \%)$ whereas the expected number was only 0.33 (OR 55.4, 95\% CI 40.8-75.2). Among these 18 cases, the following diagnostic distribution was found: diplegia 7 , hemiplegia 2, other specified 2, unspecified 7 . None had a diagnosis of mental retardation, one had a hearing deficit, and another had astigmatism and strabismus. Among the 18 boys, only three had been medically examined at military enrolment. All three had an intelligence score of 5 or 6 on a scale between 1 and 9 .

Mental retardation or epilepsy was present in four cases: both diagnoses showed an excess but neither reached significance. None of the four boys with mental retardation had been medically examined. All four with epilepsy had been medically examined and had intelligence scores in the range 5-6. Some other diagnoses appeared in numbers large enough to make analysis meaningful. None of them showed a significant excess in VLBW boys.

INTELLIGENCE TEST AND SCHOOLING

In the psychological scoring a test for intelligence is included with a scale between 1 and 9, 
Table 6 School education among 178 VLBW boys with known schooling

\begin{tabular}{lll}
\hline School & Observed & Expected \\
\hline <9 years of education & 0 & 0.2 \\
9 years of education & 6 & 3.9 \\
<3 years of "gymnasium" & 109 & 88.9 \\
3+ years of "gymnasium" & 59 & 76.4 \\
Postgymnasial education & 4 & 8.7
\end{tabular}

The Swedish "gymnasium" represents grades $10-13$ and is equivalent to upper secondary school in the UK and to senior
high school in the US.

based on test results in a four part psychological test battery. Among 221 VLBW infants tested, 51 scored below 5 (OR 4.5, 95\% CI 3.4-6.0).

Table 6 gives the distribution of completed school education levels among VLBW infants. There was an excess of boys who left early (OR $1.6,95 \%$ CI 1.2-2.2).

\section{Discussion}

We have described certain characteristics of postpubertal boys whose birthweight was below 1500 g. Few comparable long term follow up studies have been published. ${ }^{11}$ Our study was population based unlike reports from specialised neonatal intensive care centres, and the recorded variables come from routine medical examinations at national service enrolment and so are probably unbiased with respect to birthweight. However, for various reasons, a subgroup was completely excused from military enrolment examination. Reasons for this vary but one important subgroup is those who are severely handicapped. Estimates of severe handicap in the study population have therefore probably been underestimated. To estimate this error, the proportion of non-drafted individuals in the VLBW group was compared with the proportion of those with a higher birthweight. An excess was found which did not reach significance and indicated that there was a $17 \%$ higher probability for a VLBW boy not to enter the study than for a boy who weighed above $1500 \mathrm{~g}$ at birth. The estimated excess of "missed" cases in the VLBW group was only four cases, however.

The total number of boys with cerebral palsy, mental retardation, or epilepsy was $10 \%$ (26 individuals) but if all of the excess of four non-drafted individuals had such handicaps, the rate increases to $12 \%$. This rate is compatible with some of the published figures, usually based on shorter follow up. There was also an excess of low intelligence scores and of boys who had not completed 3 years of postcompulsory schooling among those who were not excused from the enrolment medical and psychological examinations. There is thus a clearcut effect on mental development although few boys developed clinical mental retardation.

We noted a clearcut effect on some other variables. Impaired vision was clearly more prevalent than expected. There was a strongly increased risk of myopia and a lesser increased risk of hyperopia. We also found a strong effect on strabismus. Hearing problems also occurred more often than expected: 15 among 221 boys tested had impaired hearing (7\%). In a prospective study of 58 children born before 32 weeks of gestation, mild hearing impairment was found in two or eight, depending on the criteria used, to which were added three multiply handicapped, retarded children, a total of 5-11 or $9-19 \% .{ }^{19}$ A single frequency specific deficit was detected in over half of the children.

Stature was shorter, body weight lower, and BMI lower in VLBW boys than in controls and there was also a reduction in muscular strength and physical working capacity. No effect on asthma risk was seen, in contrast to findings from Israel, using similar methodology but with $<2500 \mathrm{~g}$ as the low birthweight definition. ${ }^{15}$ We found no excess of other common medical diagnoses.

The cohorts studied were born in 1973-5 and many advances in neonatal care of VLBW newborns have occurred since then. This has resulted in greater survival of such infants and may also result in better long term development.

1 Ericson A, Gunnarskog J, Källén B, Otterblad-Olausson P. A registry study of very low birthweight liveborn infants in Sweden, 1973-1988. Acta Obstet Gynecol Scand 1992;71:104-11.

2 Kitchen WH, Rickards AL, Doyle LW, Ford GW, Kelly EA, Callanan C. Improvement in outcome for very low birthweight children. Med 7 Aust 1992;157:154-8.

3 Weir W, Mutch L, Camerson M, et al. The Scottish low birth weight study. 1. Survival, growth, neuromotor and sensory weight study. 1. Survival, growth, neuromoto
impairment. Arch Dis Child 1992;67:675-81.

4 Weir W, Cameron M, Cochrane M, et al. The Scottish low birthweight study. 2. Language attainment, cognitive status, and behavioural problems. Arch Dis Child 1992;67:675-81.

5 Smedler AC, Faxelius G, Bremme K, Lagerström M. Psychological development in children born with very low birth weight after severe intrauterine growth retardation a 10-year follow up study. Acta Paediatr 1992;81:197-203.

6 Klebibanov PK, Brocksgunn J, McCormick MC. Classroom behavior of very low birth weight elementary school children. Pediatrics 1994;94:700-8.

7 Hille ETM, Denouden AL, Bauer L, Van den Oudenrijn C, Brand R, Verloovevanhorick SP. School performance at nine years of age in very premature and very low birth nine years of age in very premature and very low birth weight infants: Perinatal risk factors and p

8 Kempley ST, Diffley FS, Ruiz G, Lowe D, Evans BG, Gamsu HR. Birth weight and special educational needs: Effects of an increase in the survival of very low birth weight infants in London. $\mathcal{F}$ Epidemiol Community Health 1995;49:33-7.

9 Powls A, Botting N, Cooke RWI, Marlow N. Motor impairment in children 12 to 13 years old with a birthweight less than 1250 g. Arch Dis Child 1995;73:F62-6.

10 Powls A, Botting N, Cooke RWI, Pilling D, Marlow N. Growth impairment in very low birthweight children at 12 years: Correlation with perinatal outcome variables. Arch Dis Child 1996;75:F152-7.

11 Bjerager M, Steensberg J, Greisen G. Quality of life among young adults born with very low birthweights. Acta Paediatr 1996;84:1339-43.

12 Damman O, Walther H, Allers B, et al. Development of a regional cohort of very-low-birthweight children at six years: Cognitive abilities are associated with neurological disability and social background. Dev Med Child Neurol 1996;38:97-108.

13 Stewart A, Kirkbride V. Very preterm infants at fourteen years: Relationship with neonatal ultrasound brain scans and neurodevelopmental status at one year. Acta Paediatr 1996;85(Suppl. 416):44-7.

14 Cnattingius S, Ericson A, Gunnarskog J, Källén B. A quality study of a medical birth registry. Scand $\mathcal{f}$ Soc Med 1990;18:143-8.

15 Seidman DS, Laor A, Gale R, Stevenson DK, Danon VL. Is low birth weight a risk factor for asthma during adolescence. Arch Dis Child 1991;66:584-7.

16 Green A. The Danish conscription registry: A resource for epidemiological research. Dan Med Bull 1996;43:464-7.

17 Mantel N, Haenszel W. Statistical aspects of data from retrospective studies of disease. $\mathcal{f}$ Natl Cancer Inst 1963;32:719-48.

18 Miettinen OS. Simple interval estimation of risk ratios. $\mathrm{Am}$ 7 Epidemiol 1974;100:515-6.

19 Herrgard E, Karjalainen S, Martikainen A, Heinonen K. Hearing loss at the age of 5 years of children born preterm - a matter of definition. Acta Paediatr 1995;84:1160-4. 